\title{
25 Research Square \\ The Role of Bystander Effect in Ultraviolet A Induced Photoaging
}

\section{Surajit Hansda}

University of Kalyani

\section{Gargi Ghosh}

University of Kalyani

Rita Ghosh ( $\square$ rghosh_bcbp@klyuniv.ac.in )

University of Kalyani https://orcid.org/0000-0002-7080-195X

\section{Short Report}

Keywords: UVA, Bystander response, Photoaging, Matrix metalloproteinase-1 (MMP-1), Cyclooxygenase-2 (COX-2).

Posted Date: August 13th, 2021

DOI: https://doi.org/10.21203/rs.3.rs-790933/v1

License: (c) (1) This work is licensed under a Creative Commons Attribution 4.0 International License. Read Full License 


\section{Abstract}

Background: Exposure to sunlight, mainly UVA, leads to typical changes in the features of the skin known as photoaging. UVA irradiation induces the expression of proteases that are responsible for the degradation of the extracellular matrix proteins to results in photoaging; it also downregulates the expression of proteins that are needed for the skin structure. Since, it is known that cells in the neighborhood of irradiated cells, but not directly exposed to it, often manifest responses like their irradiated counterparts, it is important to evaluate if these bystander cells too, can contribute to photoaging.

Methods and Results: UVA induced cell cycle arrest have been associated with photoaging, from flow cytometry analysis we found that there was an induction of cell cycle arrest at the $G_{1} / S$ phase in the UVAbystander cells. The expression of some key photoaging marker genes likes, matrix metalloproteinases (MMP-1, MMP-3, MMP-9), cyclooxygenase-2 (COX-2), collagen1 and elastin were assessed from qRT-PCR. Upregulation of MMP-1 and COX-2, downregulation of collagen 1 and elastin, along with suppression below normal expression for MMP-3 and MMP-9 was observed in the UVA-bystander A375 cells.

Conclusion: Our findings for the first time suggest the contribution of UVA-bystander cells to the process of photoaging.

\section{Highlights}

- $\mathrm{G}_{1} / \mathrm{S}$ cell cycle arrest was observed in UVA-bystander A375 cells.

- The expression of MMP-1 \& COX-2 was upregulated in UVA-bystander A375 cells.

- Collagen 1 \& elastin expression was also downregulated in these bystander cells.

- Expression of MMP-3 \& -9 in the UVA-bystander cells lower than that in control cells.

\section{Introduction}

Aging of the skin is a natural physiological consequence. While chronological aging is intrinsic and unavoidable; exogenous agents from the environment accelerate the process, where ultraviolet radiation (UVR) is a major factor. The skin is the largest organ of the body that is directly exposed to UVR from the sun. UVR causes injury to the skin through multiple molecular pathways that cause inflammation, sunburn, immune suppression, altered pigmentation and connective tissue damages and cancer [1]. Chronic exposure to solar UV light causes photoaging, which accelerates the natural biological aging of the skin [1]. UVA (320-400 nm) constitutes about $95 \%$ of the solar UVR that reaches the earth. The usual clinical features of photoaging share some common features with chronological aging. Photoaging is characterized by fine or coarse wrinkles, elevated fragility, sagging, blotchy dyspigmentation, roughness, dryness, laxity, epidermal thickness, dyschromia, rough skin texture and dermal and epidermal changes. 
Several genes have been associated with chronological aging of the skin that includes various stress reaction genes, anti-oxidative genes, suppressor genes and DNA repair genes. UVA radiation initiates a large range of signal transduction transcription factors to modulate the photoaging process [2]. UVR activates various matrix metallopeptidases (MMPs), which causes alterations in the proteins of the extracellular matrix (ECM). MMPs play a pivotal role in photoaging, photocarcinogenesis as well as tumour metastasis [3]. Of the 28 different MMPs found in human cells, MMP-1, -3 , and -9 , have been implicated as the key regulators during photoaging of the skin by degradation of the dermal ECM [2]. UVA directly induces MMP-1 activation that has been involved in the degradation of type-I collagen. Dermal ECM consists of a major structural protein, type-I collagen. The strength and flexibility of skin mainly depend on collagen fibrils. Diminish in collagen synthesis is also negatively regulated by UVA radiation that contributes to skin photoaging [4]. Photodamaged human skin exhibits some prominent features that include fragmentation, disorganization and dispersion of collagen. Besides regulation of MMPs and collagen, the expression of COX-2 is significantly upregulated in photoaged skin that indicated its involvement in the pathogenesis of the photoaging process [5]. UVA-related damage causes higher production of abnormal elastin that can result in the activation of MMPs. Elastin is located in the connective tissue of the skin's dermis layer. Changes in the structure of elastic fiber lead to the loss of cutaneous elasticity induced by UVR. Another major hallmark is solar elastosis, a characteristic, that is distinguished by the presence of fibrillary basophilic material.

Apart from the direct effects of radiation, there also exists of non-targeted action of radiation, a phenomenon known as bystander effect (BE), where effects of radiation can also be observed in neighboring non-irradiated cells. It is mediated through cell-cell communication through the gap junction and factors released from the exposed cells. UV irradiation is also known to release several factors that result in bystander responses in cells [6]. The bystander responses to UV radiation often depend on cell types, range of the radiation and dose. There are, however no reports available on the contribution of UVAbystander cells to photoaging of the skin. In this short report, we present our findings on the possible contribution of UVA-bystander cells to the process of photoaging by assessing the expression of some key photoaging markers genes like MMP-1, $-3,-9$, COX-2, collagen 1 and elastin.

\section{Materials And Methods}

\subsection{Cell culture and treatment}

A375 cells were grown in minimal essential media (MEM) (HiMedia) containing antibiotic antimycotic solution (HiMedia) and $10 \%$ fetal bovine serum (HiMedia) in Petri-dishes (Tarson) at $37^{\circ} \mathrm{C}$, humidified $\mathrm{CO}_{2}$ (5\%) atmosphere to maintain cells in exponential phase of growth. To obtain UVA-conditioned media (UVA-CM), medium was aspirated off and cells washed out in PBS before exposing cells to UVA (15 $\mathrm{kJ} / \mathrm{m}^{2}$ ) (Philips, 9W lamp; dose rate $6.198 \mathrm{~J} / \mathrm{m}^{2} / \mathrm{s}$ ). Irradiated cells were incubated in fresh media for 22 $\mathrm{h}$; this $\mathrm{CM}$ was then harvested and utilized to treat a new batch of non-irradiated cells for $2 \mathrm{~h}$ to acquire the UVA-bystander cells. For control, CM from unirradiated cells was used for the treatment [7]. 


\subsection{Cell cycle arrest}

The effect of the UVA-CM on cell cycle distribution in UVA-bystander cells was evaluated at various times $(0,6,12$ and $24 \mathrm{~h})$ after treatment. By staining cells with PI $(10 \mu \mathrm{g} / \mathrm{ml})($ Sigma, USA) the distribution of cell population in different phases was assessed from 10,000 cells per sample in a flow cytometer and analyzed using Flowing Software (FACS Calibur; BD Biosciences, USA) [8].

\subsection{Real Time-PCR for gene expression}

The expression of MMP-1, -3, -9, COX-2, COL1A1 (collagen 1) and elastin (ELS) mRNAs were determined in cells exposed to UVA $\left(15 \mathrm{~kJ} / \mathrm{m}^{2}\right)$ or treated with UVA-CM and compared to control. Briefly, total RNA was isolated from cells using TRIzol ${ }^{\text {TM }}$ reagents (Thermo Fischer), which was followed by Dnase I (NEB) treatment. cDNA was prepared using a random hexamer (Thermo Fisher) with MMLV reverse transcriptase (NEB). Quantitative real-time PCR or qRT-PCR was conducted using iTAq Universal SYBR Green Supermix (Bio-Rad). The relative mRNA expressions were determined by the $2^{-\triangle \Delta C t}$ method using human $\beta$-actin (ACTB) as reference [9]. The primers used for qRT-PCR amplification for these genes are shown in Table 1.

Table 1

Primers used for quantitative real-time PCR

\begin{tabular}{|lll|}
\hline Target gene & Forward primers & Reverse primers \\
\hline MMP-1 & 5' CATCGTGTTGCAGCTCATGA 3' & 5' ATGGGCTGGACAGGATTTTG 3' \\
\hline MMP-3 & 5' TTGATGGACCTGGAAATGTTTTG 3' & 5' GGGAGTGGCCAATTTCATGA 3' \\
MMP-9 & 5' GGATCCAAAACTACTCGGAAGAC 3' & 5' ACACCAAACTGGATGACGATGTC 3' \\
COX-2 & 5' TTTGGTGGAGAAGTGGGTTTTC 3' & 5' GCGGGAAGAACTTGCATTGA 3' \\
COL1A1 & 5' GAGGGCCAAGACGAAGACATC 3' & 5' CAGATCACGTCATCGCACAAC 3' \\
ELS & 5' CTTTTGGTTTTATTGTTGTGGTTCAT 3' & 5' AAAAAAGGTGTGTTTCATCCAGAGT 3' \\
ACTB & 5' TGCCGACAGGATGCAGAAG 3' & 5' GCCGATCCACACGGAGTACTT 3' \\
\hline
\end{tabular}

\subsection{Statistical analysis}

For all assays, Graphpad Prism 5.0 software was used to obtain the mean \pm standard deviation (SD) from the data of three independent experiments. ANOVA followed by Bonferroni's Post Hoc Test was used to calculate the statistical significance, where $P<0.05$ was considered.

\section{Results And Discussion}

Persistent or continuous exposure to UVA leads to photoaging, where the involvement of ROS is implicated. The generation of ROS is well documented on UVA irradiation [10]. We have observed that there was the generation of ROS, induction of DNA damage, depletion of antioxidant enzyme activities 
and lipid peroxidation in UVA exposed A375 cells; but no generation of ROS, DNA damage, lipid peroxidation, or cell killing was observed in the UVA-bystander cells (communicated). So, it was not possible to infer from those findings about the role of bystander cells in UVA-induced aging.

The integrity of the skin is largely maintained through the renewal and restructuring of damaged cells. The major factor that contributes to the injury of cells is through DNA damage from UV irradiation. Deficiency in DNA repair has been associated with skin aging. Cell cycle arrest halts the propagation of dysfunctional cells initiated by different detrimental stimuli. Blockage in the cell cycle has been linked with increased senescence from UV-mediated photoaging [11]. In fibroblast, UVA exposure led to cell cycle arrest and skin aging [12]. We have therefore observed the distribution of cells in the different phases at various times $(0,6,12$ and $24 \mathrm{~h})$ after exposure to UVA-CM to assess the influence on cell cycle progression in the UVA-bystander A375 cells. The findings are shown in Fig. 1. In the UVA-bystander cells, by $6 \mathrm{~h}$ after the $C M$ conditioning treatment, the $G_{1} / S$ cell population increased to $(80.17 \pm 0.29) \%$ from $(69.69 \pm 0.62) \%$ in control cells. This accumulation of cells in the $G_{1} / S$ phase persisted until $24 \mathrm{~h}$. We have seen earlier that UVA also induced $G_{1} / S$ arrest in $A 375$ cells [8]. Mao et al. had observed $G_{1}$ arrest in replicative senescent fibroblasts population [13]. Although cellular senescence is different, it is also associated with another form of growth arrest, known as quiescence; here arrest occurs at $\mathrm{G}_{1}$ and possibly also in the $G_{2}$ phase. Despite no induced DNA damage, the observed delay in cell cycle on exposure to UVA-CM suggests alteration of cell function that may be related to cellular photoaging in the UVA-bystander cells.

The MMPs contribute to the degradation of the extracellular matrix (ECM), significant amongst them are MMP-1, -3 and -9 that have a direct correlation with photoaging [2]. UVA irradiation induces activation of transcription factors like AP-1 and NF-KB, which are involved in the transcriptional regulation of MMPs [14]. UVA and UVB induce upregulation of MMP-1 in different cell lines [15]. MMP-1 is a multifunctional protein that is highly related to stress induced premature senescence and photo-induced wrinkling [3]; it degrades collagen 1 in the ECM. Inhibiting the expression of MMP-1 prevented photoaging in cells [16]. We found that exposure to UVA increased the expression of the MMP-1 gene. UVA-bystander A375 cells also exhibited an increase, but it was less pronounced than in UVA exposed cells (Fig. 2a). Our findings reflect the possible involvement of UVA-bystander cells in photoaging through the induction of expression of MMP-1.

Stromelycin 1 or MMP-3 is known for its role in inflammation. It also degrades collagen IV, V, IX, X, gelatin, laminin, fibronectins and also activates pro-collagenase, like pro-MMP-9 [3]. Activated MMP-9 (gelatinaseB) has a role in various physiological processes, where its function in the degradation of the ECM is important. MMP-9 can degrade elastin and hydrolyze collagen type IV in the skin [3]. Both MMP-3 and - 9 were overexpressed in UVA irradiated cells [17]. We also found upregulation of MMP-3 and MMP-9 mRNA on UVA irradiation. In the UVA-bystander cells, the expression of both these proteases was suppressed beyond that present in the control cells, as shown in Fig. 2b and 2c, respectively. The MMP-9 promoter 
contains a binding site for the NF-KB [14]. NF-KB was not induced in the UV-bystander A375 cells [18]. This may explain the transcriptional downregulation of MMP-9.

MMP-3 and MMP-9 are also biomarkers of cancer, due to their role in tumour growth, invasion and metastasis [19]. Inhibition of MMP-3 and MMP-9 can block metastasis, angiogenesis and cancer [20]. The downregulation of MMP-3 and - 9 indicated that these proteases do not contribute to photoaging in bystander cells and also suggested that the UVA-bystander effect does not increase the propensity towards cancer. This is in accordance with our earlier findings that there was no increase in the side population of cancer stem cells in the UVA-bystander cells (communicated).

Exposure to UVA activates inflammatory responses due to oxidative stress via intracellular signaling pathways in the skin. Biochemical, genetic and pharmacologic evidence indicates the pivotal role of COX2 in inflammation. Hence, UVA-mediated signaling that induces the expression of COX-2 could be a target for preventing skin inflammation [21]. COX-2 gene transcription is elevated by AP-1, which binds to a specific site on the COX-2 gene [22]. COX-2 also activated NF-KB signaling pathway in UV irradiated cells [22]. It has been demonstrated that COX-2 expression is significantly upregulated in photoaged skin; it positively correlated with the degree of solar elastosis [5]. Inhibitors of COX-2 have been found to prevent photoaging [23]. A significant upregulation in the expression of COX-2 in both, UVA irradiated cells and also in the UVA-bystander cells was observed (Fig. 2d), the extent of upregulation of COX-2 was, however much lower in the bystander cells. Through the induction of COX-2, therefore, the bystander cells had a direct role in photoaging.

Collagen provides strength and elasticity to the skin. Accumulation of degraded collagen leads to the formation of wrinkles, which is a characteristic of photoaging [4]. An increase in the expression of MMP-1 results in the breakdown of the collagen fibers. The main building blocks responsible for the de novo synthesis of collagen fibers are collagen type 1 (COL1A1). UV radiation significantly downregulates collagen through the AP-1 signaling pathway [22]. The degradation of collagen and elastin and the increase of MMPs are inversely proportional [22]. An increase in expression of MMP-1 is associated with downregulation of type I collagen protein in photoaged skin [24]. Type I and III fibrillar collagens are degraded by MMP-1; proMMP- 9, on activation by MMP-3 can further degrade collagen fragments generated by MMP-1. A decrease in expression of the COL1A1 gene was evident in both UVA exposed cells and also in the bystander cells (Fig. 2e). The decrement in the expression of COL1A1 in the bystander cells was less pronounced than that in the UVA irradiated cells.

Elastin is another important component of the ECM. Its presence in connective tissues imparts elasticity to the skin. Elastin is rich in alanine, glycine, leucine, proline and valine, which are arranged in short repeated sequences to form a highly flexible and dynamic structure. Solar elastosis arises from the degradation of elastic fibers that is integral to cutaneous photoaging [25]. Degradation of elastin leads to wrinkle and line formations in the skin [25]. The expression of elastin was remarkably downregulated in both UVA exposed cells and in its bystander cells (Fig. 2f). The reduction in the expression of elastin being more marked in the irradiated cells than in the UVA-bystander cells. The findings that both COL1A1 
and elastin are downregulated in the A375-bystander cells further endorsed the contribution of bystander cells to photoaging.

\section{Conclusion}

This is the first report studying the involvement of UVA-bystander cells in the process of photoaging. Our findings suggest that the UVA-bystander cells contribute to photoaging of the skin through modulation in the expression of some of the vital markers of photoaging, where upregulation of MMP-1 and COX-2 along with downregulation in the expression of $\mathrm{COL1A} 1$ and elastin was detected. These findings may be important for the advancement of our understanding of the range of action of photoaging in cells.

\section{Declarations}

Acknowledgements: The authors acknowledge the infrastructural facility from the University of Kalyani (K.U.), DST-PURSE and UGC-SAP, Govt. of India. Thanks are due to Dr. Utpal Basu, K.U., for some laboratory facilities.

Funding: The authors did not receive support from any organization for the submitted work.

Conflicts of interest: The authors have no relevant financial or non-financial interests to disclose.

Availability of data and material: Data will be made available on request.

Code availability: Not Applicable.

Ethics approval: Not Applicable; Studies were on cultured cells.

Consent to participate: Not Applicable.

Consent for Publication: Yes.

\section{References}

1. Quan T, Qin Z, Xia W, Shao Y, Voorhees JJ, Fisher GJ (2009) Matrix-degrading metalloproteinases in photoaging. J Investig Dermatology Symp Proc 14:20-24. https://doi.org/10.1038/jidsymp.2009.8

2. Ghosh R (2017) Role of Proteases in Photo-aging of the Skin. In: Chakraborti S, Dhalla NS (eds) Proteases in Physiology and Pathology. Springer, Singapore, pp 435-449. https://doi.org/10.1007/978-981-10-2513-6_20

3. Pittayapruek P, Meephansan J, Prapapan O, Komine M, Ohtsuki M (2016) Role of matrix metalloproteinases in Photoaging and photocarcinogenesis. Int J Mol Sci 17:1-20. https://doi.org/10.3390/ijms17060868

4. Chauhan P, Shakya M (2009) Modeling signaling pathways leading to wrinkle formation: Identification of the skin aging target. Indian J Dermatol Venereol Leprol 75:463-468. 
https://doi.org/10.4103/0378-6323.55388

5. Habib MA, Salem SAM, Hakim SA, Shalan YAM (2014) Comparative immunohistochemical assessment of cutaneous cyclooxygenase-2 enzyme expression in chronological aging and photoaging. Photodermatol Photoimmunol Photomed 30:43-51. https://doi.org/10.1111/phpp.12087

6. Widel M (2012) Bystander effect induced by UV radiation; why should we be interested? Postepy Hig Med Dosw (Online) 66:828-837. https://doi.org/10.5604/17322693.1019532

7. Ghosh R, Bhaumik G (1995) Supernatant medium from UV-irradiated cells influences the cytotoxicity and mutagenicity of V79 cells. Mutat Res Mutagen Relat Subj 335:129-135. https://doi.org/10.1016/0165-1161(95)00011-9

8. Hansda S, Ghosh G, Ghosh R (2020) 9-phenyl acridine photosensitizes A375 cells to UVA radiation. Heliyon 6:e04733. https://doi.org/10.1016/j.heliyon.2020.e04733

9. Livak KJ, Schmittgen TD (2001) Analysis of relative gene expression data using real-time quantitative PCR and the 2- $\Delta \Delta$ CT method. Methods 25:402-408. https://doi.org/10.1006/meth.2001.1262

10. Vile GF, Tyrrell RM (1995) UVA radiation-induced oxidative damage to lipids and proteins in vitro and in human skin fibroblasts is dependent on iron and singlet oxygen. Free Radic Biol Med 18:721-730. https://doi.org/10.1016/0891-5849(94)00192-M

11. Deng M, Xu Y, Yu Z, Wang X, Cai Y, Zheng H, Li W, Zhang W (2019) Protective Effect of Fat Extract on UVB-Induced Photoaging in Vitro and in Vivo. Oxid Med Cell Longev 2019:1-11. https://doi.org/10.1155/2019/6146942

12. Wlaschek M, Tantcheva-Poór I, Naderi L, Ma W, Schneider LA, Razi-Wolf Z, Schüller J, ScharffetterKochanek K (2001) Solar UV irradiation and dermal photoaging. J Photochem Photobiol B Biol 63:41-51. https://doi.org/https://doi.org/10.1016/S1011-1344(01)00201-9

13. Mao Z, Ke Z, Gorbunova V, Seluanov A (2012) Replicatively senescent cells are arrested in G1 and G2 phases. Aging 4:431-435. https://doi.org/10.18632/aging.100467

14. Steinbrenner H, Ramos MC, Stuhlmann D, Sies H, Brenneisen P (2003) UVA-mediated downregulation of MMP-2 and MMP-9 in human epidermal keratinocytes. Biochem Biophys Res Commun 308:486491. https://doi.org/10.1016/S0006-291X(03)01430-X

15. Buechner N, Schroeder P, Jakob S, Kunze K, Maresch T, Calles C, Krutmann J, Haendeler J (2008) Changes of MMP-1 and collagen type la1 by UVA, UVB and IRA are differentially regulated by Trx-1. Exp Gerontol 43:633-637. https://doi.org/10.1016/j.exger.2008.04.009

16. Wen KC, Fan PC, Tsai SY, Shih IC, Chiang HM (2012) Ixora parviflora protects against UVB-induced photoaging by inhibiting the expression of MMPs, MAP kinases, and COX-2 and by promoting type I procollagen synthesis. Evidence-based Complement Altern Med 2012:1-11. https://doi.org/10.1155/2012/417346

17. Jean C, Bogdanowicz P, Haure MJ, Castex-Rizzi N, Fournié JJ, Laurent G (2011) UVA-activated synthesis of metalloproteinases 1, 3 and 9 is prevented by a broad-spectrum sunscreen. 
Photodermatol Photoimmunol Photomed 27:318-324. https://doi.org/10.1111/j.16000781.2011.00627.x

18. Ghosh R, Guha D, Bhowmik S, Karmakar S (2012) Some UV-bystander effects are mediated through induction of antioxidant defense in mammalian cells. Indian J Biochem Biophys 49:371-378. http://nopr.niscair.res.in/handle/123456789/14837

19. Reunanen N, VeliMatti K (2013) Matrix metalloproteinases in cancer cell invasion. In: Madame Curie Bioscience Database [Internet]. Austin, TX, Landes Bioscience, USA, pp 1-19. https://www.ncbi.nlm.nih.gov/books/NBK6598/

20. Winer A, Adams S, Mignatti P (2018) Matrix metalloproteinase inhibitors in cancer therapy: Turning past failures into future successes. Mol Cancer Ther 17:1147-1155. https://doi.org/10.1158/15357163.MCT-17-0646

21. Bachelor MA, Bowden GT (2004) UVA-mediated activation of signaling pathways involved in skin tumor promotion and progression. Semin Cancer Biol 14:131-138.

https://doi.org/10.1016/j.semcancer.2003.09.017

22. Shabunin AS, Yudin VE, Dobrovolskaya IP, Zinovyev EV, Zubov V, Ivan'kova EM, Morganti P (2019) Composite wound dressing based on chitin/chitosan nanofibers: processing and biomedical applications. Cosmetics 6:16. https://doi.org/https://doi.org/10.3390/cosmetics6010016

23. Lee ME, Kim SR, Lee S, Jung YJ, Choi SS, Kim WJ, Han JA (2012) Cyclooxygenase-2 inhibitors modulate skin aging in a catalytic activity-independent manner. Exp Mol Med 44:536-544. https://doi.org/10.3858/emm.2012.44.9.061

24. Quan T, Little E, Quan H, Qin Z, Voorhees JJ, Fisher GJ (2013) Elevated matrix metalloproteinases and collagen fragmentation in photodamaged human skin: Impact of altered extracellular matrix microenvironment on dermal fibroblast function. J Invest Dermatol 133:1362-1366. https://doi.org/10.1038/jid.2012.509

25. Weihermann AC, Lorencini M, Brohem CA, de Carvalho CM (2017) Elastin structure and its involvement in skin photoageing. Int J Cosmet Sci 39:241-247. https://doi.org/10.1111/ics.12372

\section{Figures}
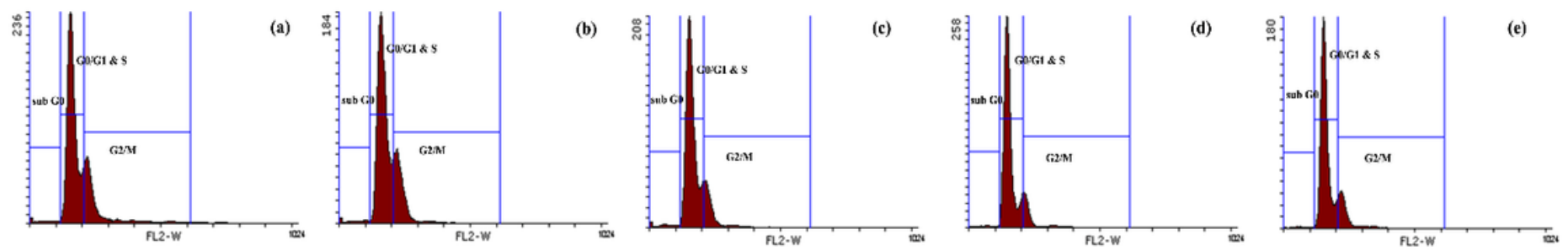

\section{Figure 1}


Typical histogram plots of cell cycle distribution in UVA-bystander A375 cells. (a) control, (b) 0, (c) 6, (d) 12 and (e) $24 \mathrm{~h}$ after UVA-CM treatment

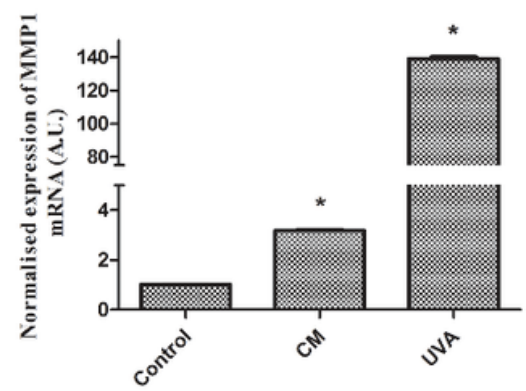

(a)

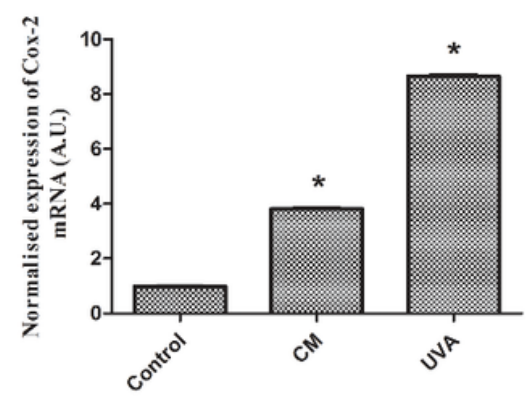

(d)

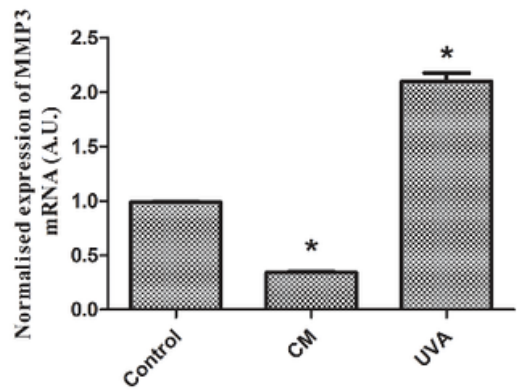

(b)

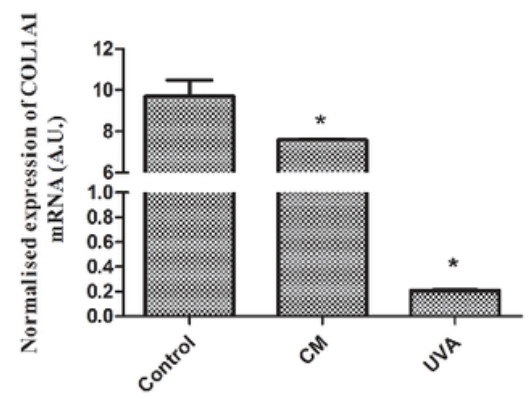

(e)

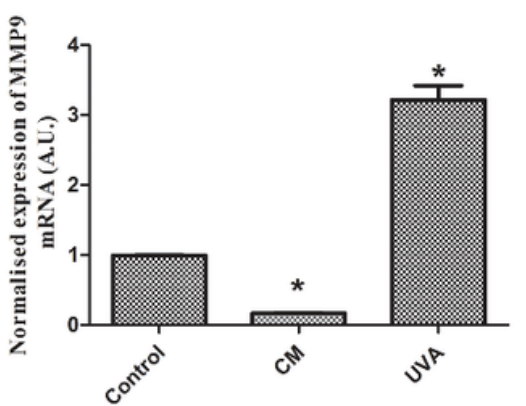

(c)

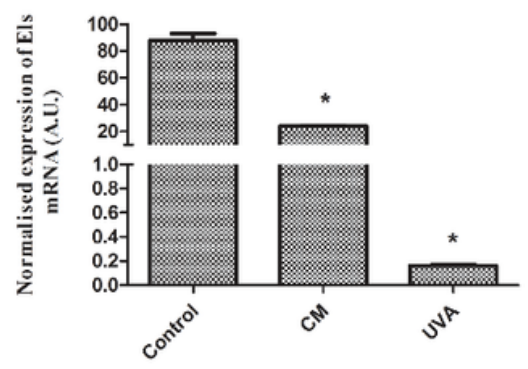

(f)

Figure 2

Bar diagram showing the relative mRNA expression in control, UVA-bystander cells and in UVA $(15 \mathrm{~kJ} / \mathrm{m} 2)$ irradiated A375 cells from qRT-PCR. mRNA levels of (a) MMP-1, (b) -3, (c) -9, (d) COX-2, (e) COL1A1 and (f) ELS. [Mean \pm SD $(n=3)$ and analyzed by one-way ANOVA. ' $*$ ' Represents the significant difference from control cells $\left.\left({ }^{\star} \mathrm{P}<0.0001\right)\right]$ 